\title{
Structural property of soybean protein P34 and specific IgE response to recombinant P34 in patients with soybean allergy
}

\author{
HIDEYUKI MORITA $^{1,2}$, HIDEO KANEKO ${ }^{1,2}$, HIDENORI OHNISHI ${ }^{1}$, ZENICHIRO KATO $^{1}$, KAZUO KUBOTA $^{1}$, \\ TAKAHIRO YAMAMOTO $^{1}$, EIKO MATSUI ${ }^{1}$, TAKAHIDE TERAMOTO ${ }^{1}$, TOSHIYUKI FUKAO $^{1}$, \\ KIMIKO KASAHARA $^{1}$ and NAOMI KONDO ${ }^{1}$ \\ ${ }^{1}$ Department of Pediatrics, Graduate School of Medicine, Gifu University; ${ }^{2}$ Department of \\ Pediatrics, Nagara Medical Center, Gifu, Japan
}

Received August 9, 2011; Accepted September 26, 2011

DOI: $10.3892 / \mathrm{ijmm} .2011 .841$

\begin{abstract}
Soybean allergy is one of the important food allergies because soybean is widely used in processed foods. P34 has been identified as the main allergen in soybeans. The main objective was to analyze the structural property of recombinant $\mathrm{P} 34$ and the $\mathrm{P} 34$ antigen-specific IgE response in soybean allergy using recombinant P34. Recombinant P34 was expressed by the BL21 (DE3) strain of Escherichia coli. Purified recombinant P34 showed oligomerization and binding to endotoxin. The binding of recombinant P34 to endotoxin was confirmed by LPS pull-down assay. Highdensity SDS treatment dissociated oligomeric recombinant P34 and removed endotoxin. Both native P34 and purified recombinant $\mathrm{P} 34$ showed almost identical structural properties as determined by circular dichroism analysis. We analyzed recombinant-P34-specific IgE antibodies by the ImmunoCAP System. In ImmunoCAP using recombinant P34, all sera from healthy controls were classified as negative. A correlation was found between the specific $\operatorname{IgE}$ antibodies to whole soybean and recombinant $\mathrm{P} 34(\mathrm{r}=0.526, \mathrm{P}<0.05)$. The sera from 3 of $9(33 \%)$ patients with outgrown soybean allergy and 6 of 9 $(66 \%)$ patients with soybean allergy were classified as positive. SDS-treated recombinant P34 retained its structure and biological activity. Recombinant P34 is a useful tool for the analysis of antigen-specific response in soybean allergy. It may be possible to develop a modified form of recombinant P34 for the diagnosis or treatment of soybean allergy using specific immunotherapy techniques.
\end{abstract}

Correspondence to: Dr Hideo Kaneko, Department of Pediatrics, Graduate School of Medicine, Gifu University, 1-1 Yanagido, Gifu 501-1194, Japan

E-mail: hideo@gifu-u.ac.jp

Abbreviations: CD, circular dichroism; DLS, dynamic light scattering; LST, lymphocyte stimulation test; rP34, recombinant P34

Key words: endotoxin, ImmunoCAP, recombinant P34, SDS, soybean allergy, specific $\operatorname{IgE}$

\section{Introduction}

Soybean is one of the main sources of protein in human nutrition $(1,2)$, and soybean is used in an increasing number of products because of its health benefits $(3,4)$. However, in the United States, approximately $0.4 \%$ of children are allergic to soybean and many infants must not be fed soybean-based formula and baby foods (5). Soybean-induced allergic symptoms may range from skin, gastrointestinal, or respiratory reactions to anaphylaxis $(5,6)$. Although the primary treatment for food allergies is to avoid the causative agent, it is difficult to avoid soy protein because of its extensive use in prepared and processed foods.

There are more than 20 soybean proteins that cause allergies (7). Recently, it has been reported that Gly $\mathrm{m} 5$ ( $\beta$-conglycinin) and Gly $\mathrm{m} 6$ cause severe allergic reactions

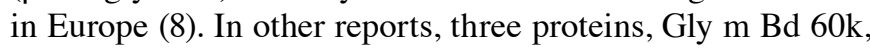
Gly $\mathrm{m}$ Bd 30k (P34), and Gly $\mathrm{m}$ Bd 28k represent the main seed allergens in soybean-sensitive patients $(9,10)$. P34 is the allergen most strongly and frequently recognized by the $\operatorname{IgE}$ antibodies in the sera of soybean-sensitive patients with atopic dermatitis $(3,11)$. In several IgE binding studies, more than $65 \%$ of soybean allergic patients with atopic dermatitis exhibited an allergic response to P34 (11-14). P34 is regarded as the major, or immunodominant, soybean allergen and is a target allergen for producing low-allergen-content hypoallergenic soybean products (15-17). Moreover, P34 shares high sequence homologies with the main peanut allergen Ara $h$ 1, the dust mite allergen Der p 1, cow's milk caseins, and papain (18-20). Thus, peanuts and soybeans contain common allergenic components and, for this reason, $\mathrm{IgE}$ antibodies to peanut proteins may cross-react with soybean proteins.

First, we tried to express recombinant P34 (rP34) in Escherichia coli using a previously reported method (21). However, recombinant proteins expressed in E. coli carry the risk of endotoxin contamination. Endotoxin causes falsepositive results in biological-cell-based assays, such as the cell proliferation assay and must be removed particularly when evaluating allergen-stimulated $\mathrm{T}$ cell proliferation (22). The methods for removing endotoxin vary greatly and depend on the structure and characteristics of particular allergens $(13,22,23)$. 
On the other hand, for serological diagnosis of soybean allergy, specific IgE antibodies to soybean proteins can be detected using commercially available tests. However, these tests are unsatisfactory for the identification of patients with soybean allergy. Specific IgE antibodies to major allergens in other foods, such as omega- 5 gliadin, are highly useful for the diagnosis of food allergies (24). The measurement of specific IgE antibodies to rP34 may be useful. Furthermore, for a precise serological diagnosis, a tertiary folded soluble recombinant allergen protein is necessary.

In this study, we expressed rP34 using an E. coli expression system for the evaluation of clinical manifestation. Our purified $\mathrm{rP} 34$ had almost identical structural properties to native P34. Furthermore, ImmunoCAP System using rP34 was carried out to analyze the specific IgE antibodies to P34 in patients with and without soybean allergy.

\section{Materials and methods}

Soybean extracts. Soybean (Fukuyutaka) flakes from commercial sources were ground to a fine powder using pestle and mortar and extracted by incubation with $20 \mathrm{mmol}$ sodium phosphate and $1 \mathrm{mmol}$ sodium chloride $(1: 20 \mathrm{wt} / \mathrm{vol}$, $\mathrm{pH}$ 7.2) overnight at $4^{\circ} \mathrm{C}$. Soybean mRNA was obtained using an RNeasy Plant Mini kit (Qiagen). Reverse transcription was carried out using an RNasin ribonuclease inhibitor (Promega) and M-MLV reverse transcriptase (Invitrogen). The sense and antisense primers used for PCR were designed on the basis of the cDNA sequences: 5'-GATTCGATCGAAGGTCGTAAGAAA ATGAAGAAGGAAC-3' for the sense primer and 5'-GCGGCC GCAAGAGGAGAGTGATCAACTCTTC-3' for the antisense primer. The resulting DNA fragment was purified using a Gene Clean kit, ligated to a pUC118 plasmid, and transformed into the E. coli strain JM109. The resulting plasmid, pUC118/ P34, was digested with EcoRI and NotI, and the fragment containing the P34 gene was inserted into pET24b and expressed in E. coli BL21 (DE3). The initial expression, purification and refolding of rP34 were performed in accordance with the method of Babiker et al (21).

Purification of histidine-tagged recombinant P34 using Ni Sepharose column. rP34 was purified using a Ni Sepharose column (Ni Sepharose 6 Fast Flow, $5 \mathrm{ml}$, GE Healthcare). The bound protein was eluted with $20 \mathrm{ml}$ of $100 \mathrm{mM}$ phosphate buffer containing $500 \mathrm{mM}$ imidazole, $\mathrm{pH}$ 7.4.

Conformational change of recombinant P34. To produce the monomeric form of $\mathrm{P} 34$, we used a previously reported method with modification (14). The homogeneity of rP34 was determined by dynamic light scattering (Dyna Pro-99, Proterion). The solution containing the oligomeric form of $\mathrm{rP} 34$ was treated with an equivalent volume of $4 \%$ SDS solution containing $10 \%$ 2-ME and heated at $98^{\circ} \mathrm{C}$ for $10 \mathrm{~min}$. The solution was then loaded onto a Sephacryl S-200 column pre-equilibrated with $0.1 \mathrm{M}$ sodium phosphate buffer ( $\mathrm{pH}$ 7.6) containing 1\% SDS and $10 \mathrm{mM}$ 2-ME. The column was run at $20^{\circ} \mathrm{C}$ using the same buffer and the fractions containing P34 were collected.

Endotoxin removal from recombinant P34. Detoxi-Gel (Pierce) was used to remove contaminating endotoxin in accordance with the manufacturer's instructions. The collected samples were dialyzed against $50 \mathrm{mM}$ sodium phosphate buffer ( $\mathrm{pH}$ 7.6) overnight at $4^{\circ} \mathrm{C}$. The level of endotoxin was measured by a chromogenic limulus amebocyte lysate assay (endotoxin single test; Wako Pure Chemical Industries). The collected sample was dialyzed against $50 \mathrm{mM}$ sodium phosphate buffer ( $\mathrm{pH} 7.6$ ) overnight at $4^{\circ} \mathrm{C}$ to remove any remaining SDS and stored at $-20^{\circ} \mathrm{C}$.

Endotoxin was also removed by Triton X-114 phase separation, as described by Liu et al (25). Triton X-114 was added to rP34 to a final concentration of $1 \%$ and incubated for $30 \mathrm{~min}$ at $4^{\circ} \mathrm{C}$ with constant stirring, followed by a 10 -min incubation at $37^{\circ} \mathrm{C}$ and centrifugation at $20,000 \mathrm{x}$ g at $25^{\circ} \mathrm{C}$ for $10 \mathrm{~min}$.

$N$-terminal sequencing of recombinant P34. After separation by SDS-PAGE for $1 \mathrm{~h}$ at $200 \mathrm{~mA}$ in $25 \mathrm{mM}$ Tris, $192 \mathrm{mM}$ glycine, and $10 \%$ methanol, the proteins were electroblotted onto a polyvinylidene difluoride membrane (Amersham Biosciences). The membrane was briefly stained with CBB R250 (Wako, Japan) and destained extensively in 45 and $90 \%$ methanol solutions containing $7 \%$ acetic acid. Amino acid sequence analysis of rP34 was carried out using an Edman degradation technique using a pulse liquid automatic sequencer (Model 491HT, Applied Biosystems).

Circular dichroism $(C D)$. For SDS-treated proteins, SDS concentrations of 0,1 and $4 \%\left(0,3.5 \times 10^{-2}\right.$ and $\left.1.4 \times 10^{-1} \mathrm{M}\right)$ were used. Optically clear solutions in phosphate buffer were used to record CD spectra $(195-250 \mathrm{~nm})$ in a $1 \mathrm{~mm}$ rectangular quartz cell (JASCO) using a CD spectrometer (JASCO). The secondary structure was determined by visual assessment of the spectra and using the computer program CDPro. Native P34 was provided by Professor S. Nagaoka of Gifu University.

Dynamic light scattering (DLS). DLS was carried out using a DynaPro-99 molecular-sizing instrument equipped with a microsampler (Protein Solutions). rP34 samples containing 0 , 1 and 4\% SDS were used in the experiment. The DynaPro-99 instrument was operated in accordance with the DLS machine protocol to estimate the molecular weight of rP34. Data were analyzed using the Dynamics 5.0 software (Protein Solutions).

LPS pull-down assay. A pull-down assay of the recombinant protein using labeled LPS was carried out as previously described $(26,27)$. Briefly, $10 \mu \mathrm{g}$ of biotinylated LPS (Alexis Biochemicals) was absorbed onto $20 \mu 1$ of streptavidin agarose (Vector Laboratories) and incubated with $10 \mu \mathrm{g}$ of LPS-free rP34 at room temperature for $1 \mathrm{~h}$. After washing with PBS containing $0.1 \%$ Triton $\mathrm{X}-100$, the precipitated protein was detected by silver staining.

Homology modeling of P34. The $31 \mathrm{kDa}$ cysteine protease SPE31 (PDB code, $2 \mathrm{bl} \mathrm{m}$ ) was selected from a protein databank (www.rcsb.org/pdb) as the most homologous template for P34. The structural modeling of P34 was performed using the MOE software (Chemical Computing Group, Inc.).

Subjects. Patients with a history of soybean allergy were selected as subjects of this study (Table I), and grouped on the basis of the results of the open challenge test or the accidental 
episodes of ingestion as follows: the outgrown group $(n=9)$ had a history of soybean allergy and produced soybean-specific $\mathrm{IgE}$, but was currently tolerant to soybean; the allergic group $(n=9)$ was reactive to soybean; and the healthy control group $(n=13)$ was negative for all allergens in ImmunoCAP System (Phadia AB, Uppsala, Sweden) and had no history of food allergies. Five patients (Patients 11, 13, 15, 16 and 18) had allergic reactions (urticaria, cough and wheeze) within $2 \mathrm{~h}$ after soybean ingestion, and six patients (Patients 10, 12-15 and 17) had skin symptoms after more than two hours. Informed consent was obtained from the families of all the subjects.

Western blot analysis. Western blotting using an anti-P34 monoclonal antibody was carried out in accordance with the method of Tsuji et al (28). Samples were electrophoresed on $15-25 \%$ gradient gels (XV PANTERA GEL). Separated proteins were then transferred onto membranes using an iBlot system (Invitrogen) at $30 \mathrm{~mA}$ for $14 \mathrm{~min}$. The membranes were blocked with blocking buffer (20 mM Tris, $\mathrm{pH} 7.5,150 \mathrm{mM}$ $\mathrm{NaCl}, 3 \% \mathrm{BSA}$ ) for $2 \mathrm{~h}$ at room temperature. After two 5-min washes in TBS-T, they were reacted with the patients' sera for $2 \mathrm{~h}$. After washing four times, the blots were incubated with goat anti-human IgE conjugated to HRP $(1: 5,000)$ for $2 \mathrm{~h}$. Blots were washed four times as described above. The P34 monoclonal antibody was a kind gift from Professor T. Ogawa of Kyoto University.

Specific IgE antibody. The level of specific IgE antibody to our rP34 in these patients was measured by ImmunoCAP System. In the case of using an undiluted reagent, ImmunoCAP enables the quantification of specific serum $\mathrm{IgE}$ antibodies in the range of 0.35 to $100 \mathrm{kUA} / 1$. However, for comparative purposes, the above-mentioned range is often converted into 7 scores, in accordance with the internal calibrator system, as follows: class 0 , negative; class $1,0.35-0.7 \mathrm{kUA} / \mathrm{l}$; class 2 , 0.7-3.5 kUA/1; class 3, 3.5-17.5 kUA/1; class 4, 17.5-50 kUA/l; class 5, 50-100 kUA/l; and class 6, >100 kUA/l. IgE levels $>0.35 \mathrm{kUA} / 1$ in serum are considered to indicate positivity for $\mathrm{IgE}$ by the manufacturer.

Statistical analysis. Pearson's correlation coefficient was used to estimate correlations between two numerical variables. P-values $<0.05$ are considered statistically significant.

\section{Results}

High-density SDS-treatment was useful for removal of endotoxin from rP34. The purified rP34 was detected using an anti-P34 monoclonal antibody (Fig. 1A). The $\mathrm{N}$-terminal amino acid sequence of the recombinant protein (KKMKKEQTS) was identical to that of soybean P34 (amino acid number, 123-131). As mentioned above, recombinant proteins expressed in $E$. coli carry the risk of endotoxin contamination. To remove endotoxin from this protein, $\mathrm{rP} 34$ was applied to the endotoxin removal column. However, all of the proteins absorbed onto the column. To further investigate the binding ability of P34 to LPS, we performed pull-down assay. LPS was clearly pulled down with rP34 (Fig. 2). We found that high-density SDS treatment, but not Triton X-114 treatment, dissociated oligomeric recombinant P34 and
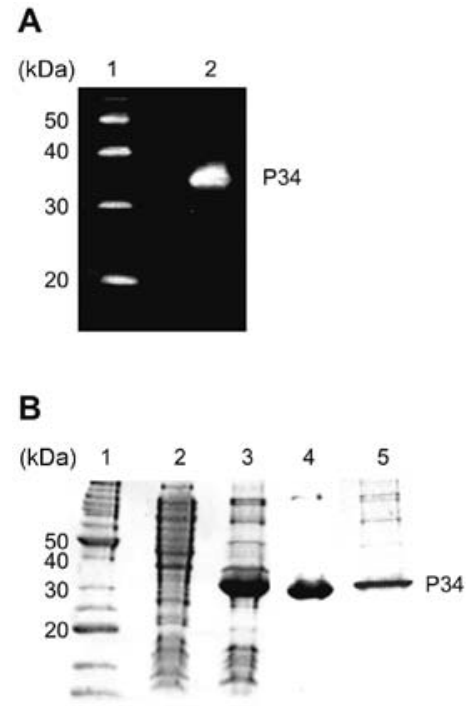

Figure 1. Purification of recombinant P34. (A) Immunoblot of recombinant P34 with an anti-P34 monoclonal antibody (1:3,000). Lane 1, molecular weight marker; lane 2, recombinant P34. (B) SDS-PAGE using a 15\% gel. Polypeptides were visualized by Coomassie blue staining. Lane 1, molecular weight marker; lane 2, soluble fraction; lane 3, insoluble fraction; lane 4, refolded protein; lane 5, recombinant P34 without endotoxin.

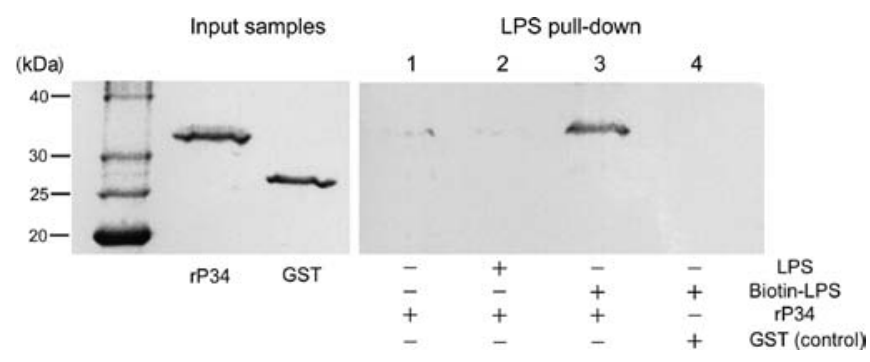

Figure 2. LPS pull-down assay. Lane 1, $10 \mu \mathrm{g}$ of recombinant P34 was incubated with $30 \mu \mathrm{l}$ of packed avidin beads. Lanes 2-3,10 $\mu \mathrm{g}$ of recombinant P34 was incubated with $10 \mu \mathrm{g}$ of non-biotinylated (lane 2) or biotinylated LPS (lane 3) and $30 \mu 1$ of packed avidin beads. Lane 4, GST protein was added as a control. After washing, recombinant P34 bound to LPS was detected by silver staining.

removed endotoxin. The final yield of purified rP34 decreased to $\sim 40 \%$ of that in the sample prior to endotoxin removal (Fig. 1B). The final yield after purification was about $11.6 \mathrm{mg} / \mathrm{l}$ of LB medium culture.

Both native P34 and SDS-treated endotoxin-free rP34 showed almost identical structural properties. SDS-induced structural conformation changes were determined from the appearance of a minimum peak at $205 \mathrm{~nm}$ and a weak shoulder at $222 \mathrm{~nm}$ in the CD spectra. No significant differences were observed between native P34 and SDS-treated rP34 in terms of the shape of the CD spectra and molar ellipticity values at $222 \mathrm{~nm}$, which reflect the $\alpha$ helix content of the folded protein (Fig. 3). It should be noted that there was actually a minor difference between native and rP34, but this may be attributable to the C-terminal hexa-histidine tag.

Structurally, P34 belongs to the papain family, whose individual members share a common mechanism of catalysis. The model of the P34 structure was constructed on the basis of the structure of the papain-like protein family protein SPE31 


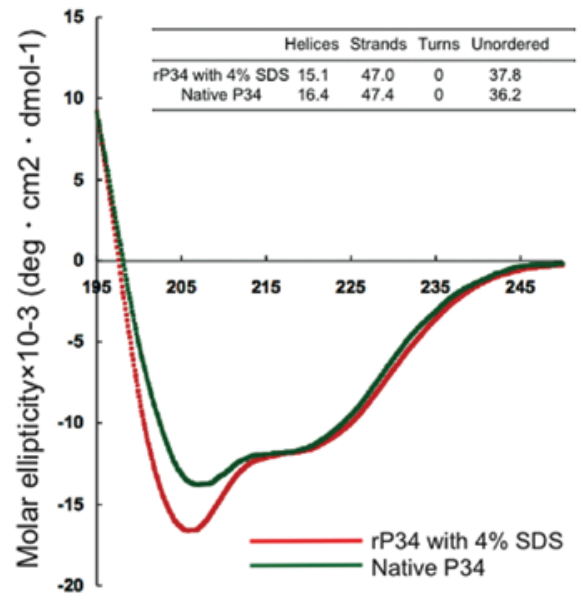

Figure 3. Circular dichroism spectra of native P34 and recombinant P34 exposed to SDS. The secondary structures of both native and recombinant P34 after SDS treatment were estimated using a computer program (CDPro).

(Fig. 4). Analysis of the sequence alignments for P34 identified SPE31 as sharing 78\% sequence identity (29). The overall structure of P34 contains two independent domains, namely, the $\mathrm{L}$ domain and $\mathrm{R}$ domain, which form a cleft. The major secondary structural part of the $\mathrm{L}$ domain forms the $\beta$-sheet and that of the $\mathrm{R}$ domain forms the $\alpha$-helix.

Reactivity of IgE in sera from soybean allergic patients to rP34 examined by Immuno CAP System. A total of 31 sera (13 controls, 9 outgrown, and 9 patients with soybean allergy) were available for the present study. The levels of rP34-specific IgE antibodies in the sera from outgrown and allergic patients measured by ImmunoCAP System are shown in Table I. Among the 31 sera investigated, 9 were positive for the specific IgE antibodies to rP34 and 22 were negative. A correlation was found between specific IgE antibodies to soybean and $\mathrm{rP} 34$. The correlation value was 0.526 and $\mathrm{P}<0.05$. All sera from healthy controls were negative for the antibodies. Six of the $9(66 \%)$ outgrown and 3 of the $9(33 \%)$ allergic patients were also negative for the antibodies. The positive sera belonged to class 1 ( 4 sera), class 2 ( 3 sera) and class 3 ( 2 sera). No serum belonged to classes 4 to 6 . Four of 5 patients with sera belonging to class 2 or 3 were not tolerant to soybean. The median concentrations of specific IgE antibodies to $\mathrm{rP} 34$ were $1.63 \mathrm{kUA} / \mathrm{l}$ (range, 0.35-5.00) in the allergic group and $0.50 \mathrm{kUA} / 1$ (range, $0.35-1.26$ ) in the outgrown group.

\section{Discussion}

Recently, recombinant allergens have become available for diagnostic and therapeutic purposes $(23,30,31)$. It is particularly important to evaluate $\mathrm{T}$ cell activation for diagnosis and specific immunotherapy using allergens. However, the use of recombinant antigens contaminated with endotoxin leads to nonspecific cytokine production and affects $\mathrm{T}$ cell proliferation, thereby masking any antigen-specific responses. In our previous study, we showed that endotoxin-free rP34 might be a useful tool for evaluation of soybean allergy (32). It is essential to remove endotoxin from recombinant proteins before using them in the analysis of antigen-specific responses.

During the processes of protein purification, we noted a strong affinity of $\mathrm{rP} 34$ to endotoxin derived from the host strain. In this study, we clearly showed the LPS binding ability of P34 by the LPS pull-down assay (Fig. 2). It is reported that P34 contains many hydrophobic residues and is, thus, insoluble in aqueous solutions (16). The structural model of rP34 (Fig. 4C) indicated that many of the hydrophobic residues (shown in yellow) are located superficially, and thus may contribute to the strong affinity of rP34 to endotoxin. On the other hand, DLS analysis showed that $\mathrm{rP} 34$ treated with $4 \%$ SDS had a molecular weight of $34.9 \mathrm{kDa}$, whereas non-SDStreated $\mathrm{rP} 34$ had a molecular weight of $790 \mathrm{kDa}$, indicating that SDS treatment disrupted the rP34 oligomers. This finding was consistent with the finding of a previous study, in which Ogawa et al (14) isolated native P34 in its oligomeric form $(>300 \mathrm{kDa})$. In our recent study and in this study, it was also possible that these SDS-induced conformational changes enabled the separation of endotoxin from rP34 (32). From this findings, we speculated that the oligomerization property of P34 may influence its affinity to endotoxin.

It was reported that P34 is a receptor of the glycolipid elicitor syringolide produced by Pseudomonas syringae
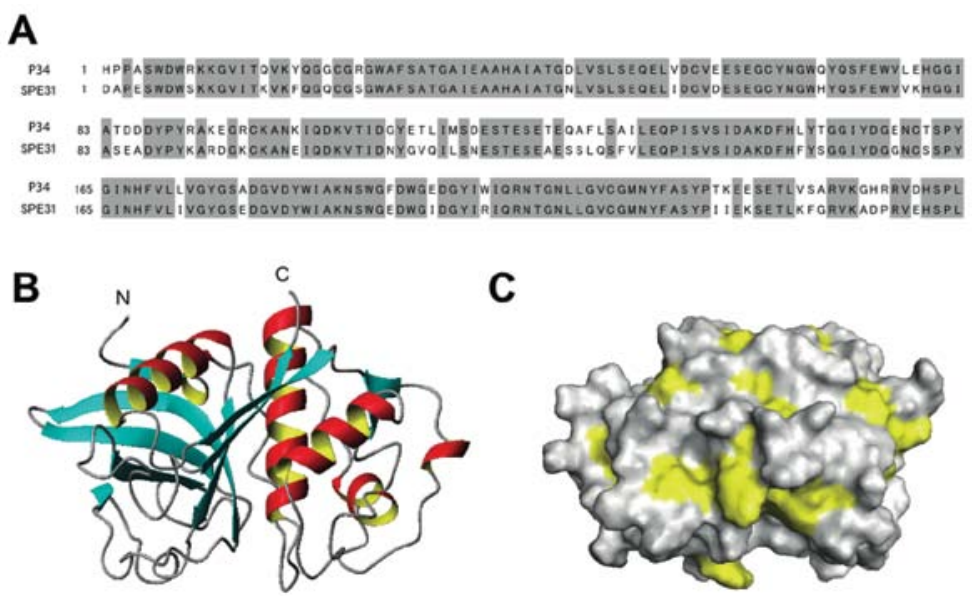

C

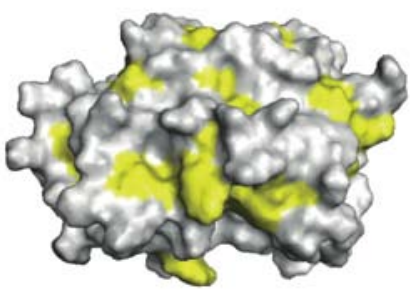

Figure 4. Structural model of recombinant P34. (A) Alignment of P34 and SPE31 amino acid sequences. P34 shares $78 \%$ amino acid sequence identity with SPE31. (B) Structural model of mature P34. (C) Distribution of hydrophobic residues on P34. The hydrophobic residues are shown in yellow. 
Table I. Characteristics of outgrown subjects and soybean allergic subjects.

ImmunoCAP values

\begin{tabular}{|c|c|c|c|c|c|c|c|c|}
\hline \multirow[b]{3}{*}{ Patient } & \multirow[b]{3}{*}{ Gender } & \multirow[b]{3}{*}{ Age (years) } & \multirow{3}{*}{$\begin{array}{l}\text { Symptoms caused by } \\
\text { soybean intake }\end{array}$} & \multirow{3}{*}{$\begin{array}{c}\text { Total IgE } \\
\text { (IU/ml) }\end{array}$} & \multirow{2}{*}{\multicolumn{2}{|c|}{ Soybean }} & & \\
\hline & & & & & & & \multicolumn{2}{|c|}{ rP34 } \\
\hline & & & & & Class & $\mathrm{kUA} / \mathrm{l}$ & Class & $\mathrm{kUA} / \mathrm{l}$ \\
\hline 1 & M & 6 & Outgrown & 3,540 & 2 & 4.14 & 2 & 1.26 \\
\hline 2 & $\mathrm{~F}$ & 1 & Outgrown & 133 & 1 & 1.40 & 1 & 0.56 \\
\hline 3 & M & 4 & Outgrown & 156 & 0 & $<0.35$ & 0 & $<0.35$ \\
\hline 4 & $\mathrm{M}$ & 5 & Outgrown & 233 & 2 & 0.84 & 0 & $<0.35$ \\
\hline 5 & M & 4 & Outgrown & 108 & 2 & 1.07 & 0 & $<0.35$ \\
\hline 6 & $\mathrm{M}$ & 3 & Outgrown & 377 & 2 & 1.94 & 0 & $<0.35$ \\
\hline 7 & $\mathrm{~F}$ & 2 & Outgrown & 426 & 2 & 2.14 & 0 & $<0.35$ \\
\hline 8 & $\mathrm{~F}$ & 3 & Outgrown & 374 & 2 & 3.60 & 1 & 0.61 \\
\hline 9 & M & 9 & Outgrown & 977 & 2 & 1.02 & 0 & $<0.35$ \\
\hline 10 & M & 1 & Urticaria & $>16,000$ & 5 & 88.2 & 3 & 5.00 \\
\hline 11 & M & 4 & Wheeze, urticaria & 1,960 & 4 & 20.9 & 2 & 1.13 \\
\hline 12 & $\mathrm{M}$ & 2 & Erythema & 31 & 1 & 0.59 & 0 & $<0.35$ \\
\hline 13 & $\mathrm{~F}$ & 1 & Cough, urticaria & 626 & 2 & 1.63 & 0 & $<0.35$ \\
\hline 14 & F & 1 & Urticaria & 23.2 & 0 & $<0.35$ & 0 & $<0.35$ \\
\hline 15 & $\mathrm{M}$ & 6 & Cough, urticaria & 1,490 & 5 & 76.4 & 1 & 0.41 \\
\hline 16 & $\mathrm{M}$ & 1 & Wheeze, urticaria & 2,460 & 3 & 9.31 & 3 & 3.61 \\
\hline 17 & M & 2 & Urticaria & 1,850 & 6 & $>100$ & 1 & 0.45 \\
\hline 18 & $\mathrm{~F}$ & 6 & Wheeze, urticaria & $>16,000$ & 5 & 57.1 & 2 & 2.93 \\
\hline
\end{tabular}

$(29,33)$. This suggests that P34 plays an important role in plant defenses against bacteria. Endotoxin is also recognized as a glycolipid elicitor and can induce defense responses in rice cells, including reactive oxygen generation and defense-gene expression. Both endotoxin and syringolide have considerable similarities in their immunological roles as pathogen-associated molecular patterns (PAMPs) (34). This suggests that P34 also recognizes the endotoxin in soybean in a manner similar to that of the Toll-like receptor 4 (TLR-4), MD-2, and CD14 in the mammalian innate immune systems (34-36). It is of particular interest that a recent report showed that the LPS-binding protein Der $\mathrm{p} 2$ which is one of the major allergens of house dust mites, modulates mouse TLR-4 signaling and is associated with atopic dermatitis (37). Trompette et al (37) suggested that lipid-binding proteins possess the intrinsic adjuvant activity that underlies the phenomenon of allergenicity. The endotoxin binding ability of P34 may also be associated with allergic reactions in humans through a similar mechanism.

A previous report has described the linear B cell epitope on P34 (13). However, the conformational B cell epitopes on P34 remain to be fully elucidated. It is desirable to maintain the three-dimensional structure of $\mathrm{P} 34$, both for accurate evaluation of $\mathrm{T}$ cell responses and for the elucidation of conformational epitopes. High-density SDS may cause conformational changes in proteins. In a previous report, $\mathrm{CD}$ analysis of soybean glycinin (11S) and $\beta$-conglycinin showed that SDS treatment increased both the $\alpha$-helical and unordered structures of both proteins at the expense of the $\beta$-sheet structure (38). In this case, the relatively low-density SDS treatment $\left(2 \times 10^{-3} \mathrm{M}\right)$ may have changed the conformation of these proteins. However, in the present study, no significant changes in the secondary structure of P34 occurred after high-density SDS treatment. Estimation of the secondary structure from the recorded CD spectra indicated no significant differences between non-SDS-treated native P34 and SDS-treated rP34 (Fig. 3). This suggests that both of the proteins form a similar folding pattern. Both CD and DLS analyses indicated that $\mathrm{rP} 34$ retained its secondary structure even after high-density SDS treatment. Our purified rP34 is useful for the analysis of linear or tertiary epitopes because it retains the tertiary structure of its protein.

We established the method using the ImmunoCAP system with purified rP34 for the first time. Measurement of the concentration of specific IgE antibodies to $\mathrm{rP} 34$ is more useful than IgE Western blotting (data not shown). A correlation was found between specific IgE antibodies to soybean and rP34. Patient 16, whose serum with specific IgE antibody to soybean had a relatively low score of 3 , showed severe allergic reactions within two hours after soybean ingestion. It is assumed that the allergic reaction in this patient was caused mainly by P34 in soybean. On the other hand, the finding that patients 15 and 17 showed a high score for their serum with specific IgE antibodies to soybean but a low score of 1 for specific IgE antibodies to $\mathrm{rP} 34$ may indicate an allergic reaction to soy protein other than P34. These results showed that the rP34 ImmunoCAP system we established could play a role as a soy allergic diagnostic tool or could indicate outgrown allergy.

In conclusion, our proposed new purification method for rP34 did not affect the tertiary protein structure. The strong affinity of P34 for endotoxin/LPS suggests that P34 may modulate the immunological responses underlying allergenicity. 
Furthermore, the ImmunoCAP system using our purified rP34 that retains its tertiary structure may be useful for the identification of patients with soybean allergy or for the indication of outgrown allergy.

\section{Acknowledgements}

We are grateful to Professor T. Ogawa of Kyoto University and S. Nagaoka of Gifu University for providing the anti-P34 antibody and native P34. This study was in part funded by the Research and Development Program for New Bio-industry Initiatives (2005-2009) of the Bio-oriented Technology Research Advancement Institution (BRAIN), Japan.

\section{References}

1. Franck P, Moneret Vautrin DA, Dousset B, Kanny G, Nabet P, Guenard-Bilbaut L and Parisot L: The allergenicity of soybeanbased products is modified by food technologies. Int Arch Allergy Immunol 128: 212-219, 2002.

2. Lusas EW and Riaz MN: Soy protein products: processing and use. J Nutr 125: 573-580, 1995.

3. Wilson S, Blaschek K and de Mejia E: Allergenic proteins in soybeans: Processing and reduction of P34 allergenicity. Nutr Rev 63: 47-58, 2005.

4. Herian AM, Taylor SL and Bush RK: Identification of soybean allergens by immunoblotting with sera from soy-allergic adults. Int Arch Allergy Appl Immunol 92: 193-198, 1990.

5. Savage JH, Kaeding AJ, Mastui EC and Wood RA: The natural history of soy allergy. J Allergy Clin Immunol 125: 683-686, 2010.

6. Herman E: Soybean allergenicity and suppression of the immunodominant allergen. Crop Sci 45: 462-467, 2005.

7. Babiker EE, Hiroyuki A, Matsudomi N, Iwata H, Ogawa $\mathrm{T}$ and Bando N: Effect of polysaccharide conjugation or transglutaminase treatment on the allergenicity and functional properties of soy protein. J Agric Food Chem 46: 866-871, 1998.

8. Holzhauser T, Wackermann O, Ballmer-Weber BK, BindslevJensen C, Scibilia J, Perono-Garoffo L, Ustumi S, Poulsen LK and Vieths S: Soybean (Glycine max) allergy in Europe: Gly m 5 (beta-conglycinin) and Gly $\mathrm{m} 6$ (glycinin) are potential diagnostic markers for severe allergic reactions to soy. J Allergy Clin Immunol 123: 452-458, 2009.

9. Herman EM, Helm RM, Jung R and Kinney AJ: Genetic modification removes an immunodominant allergen from soybean Plant Physiol 132: 36-43, 2003.

10. Ogawa T, Samoto M and Takahashi K: Soybean allergens and hypoallergenic soybean products. J Nutr Sci Vitaminol 46: 271-279, 2000.

11. Ogawa T, Bando H, Tsuji H, Okajima K and Sasaoka K: Investigation of the IgE-binding proteins in soybeans by immunoblotting with the sera of the soybean-sensitive patients with atopic dermatitis. J Nutr Sci Vitaminol (Tokyo) 37: 555-565, 1991

12. Helm RM, Cockrell G, Herman E, Burks AW, Sampson HA and Bannon GA: Cellular and molecular characterization of a major soybean allergen. Int Arch Allergy Immunol 117: 29-37, 1998.

13. Helm RM, Cockrell G, Connaughton C, West CM, Herman E, Sampson H, Bannon GA and Burks AW: Mutational analysis of the IgE-binding epitopes of P34/Gly m Bd 30K. J Allergy Clin Immunol 105: 378-384, 2000.

14. Ogawa T, Tsuji H, Bando N, Kitamura K, Zhu Y, Hirano H and Nishikawa K: Identification of the soybean allergenic protein, Gly $\mathrm{m}$ Bd $30 \mathrm{~K}$, with the soybean seed 34-kDa oil-body-associated protein. Biosci Biotech Biochem 57: 1030-1033, 1993.

15. Yaklich RW, Helm RM, Cookrell G and Herman EM: Analysis of the distribution of the major soybean seed allergens in a core collection of glycine max accessions. Crop Sci 39: 1444-1447, 1999.

16. Kalinski A, Weisemann JM, Matthews BF and Herman EM Molecular cloning of a protein associated with soybean seed oil bodies that is similar to thiol proteases of the papain family. J Biol Chem 265: 13843-13848, 1990.

17. Morishita N, Kamiya K, Matsumoto T, Sakai S, Teshima R, Urisu A, Moriyama T, Ogawa T, Akiyama $\mathrm{H}$ and Morimatsu F: Reliable enzyme-linked immunosorbent assay for the determination of soybean proteins in processed foods. J Agric Food Chem 56: 6818-6824, 2008.
18. Sicherer SH, Sampson HA and Burks AW: Peanut and soy allergy: a clinical and therapeutic dilemma. Allergy 55: 515-521, 2000.

19. Eigenmann PA, Burks AW, Bannon GA and Sampson HA: Identification of unique peanut and soy allergens in sera adsorbed with cross-reacting antibodies. J Allergy Clin Immunol 98: 969-978, 1996

20. Rozenfeld P, Docena GH, Anon MC and Fossati CA: Detection and identification of a soy protein component that cross-reacts with caseins from cow's milk. Clin Exp Immunol 130: 49-58, 2002.

21. Babiker EE, Azakami H, Ogawa T and Kato A: Immunological characterization of recombinant soy protein allergen produced by Escherichia coli expression system. J Agric Food Chem 48: 571-575, 2000.

22. Velickovic TC, Thunberg S, Polovic N, Neimert-Andersson T, Groulund $\mathrm{H}$, Hage $\mathrm{M}$ and Gafvelin G: Low levels of endotoxin enhance allergen-stimulated proliferation and reduce the threshold for activation in human peripheral blood cells. Int Arch Allergy Immunol 146: 1-10, 2008.

23. Saarne T, Kaiser L, Gronlund H, Rasool O, Gafvelin G and Hansten $\mathrm{H}$ : Rational design of hypoallergens applied to the major cat allergen Fel d 1. Clin Exp Allergy 35: 657-663, 2005.

24. Matsuo H, Dahistrom J, Tanaka A, Kohno K, Takahashi H, Furumura M and Morita E: Sensitivity and specificity of recombinant $\omega-5$ gliadin-specific IgE measurement for the diagnosis of wheat-dependent exercise-induced anaphylaxis. Allergy 63: 233-236, 2008

25. Liu S, Tobias R, McClure S, Styba G, Shi Q and Jackowski G: Removal of endotoxin from recombinant protein preparations. Clin Biochem 30: 455-463, 1997.

26. Visintin A, Latz E, Monks BG, Espevik T and Golenbock DT: Lysines 128 and 132 enable lipopolysaccharide binding to MD-2, leading to toll-like receptor-4 aggregation and signal transduction. J Biol Chem 278: 48313-48320, 2003.

27. Koraha J, Tsuneyoshi N, Kimoto M, Gauchat JF, Nakatake H and Fukudome K: Comparison of lipopolysaccharide-binding functions of CD14 and MD-2. Clin Diagn Lab Immunol 12: 1292-1297, 2005.

28. Tsuji H, Bando N, Kimoto M, Okada N and Ogawa T: Preparation and application of monoclonal antibodies for a sandwich enzymelinked immunosorbent assay of the major soybean allergen, Gly m Bd 30K. J Nutr Sci Vitaminol (Tokyo) 39: 389-397, 1993.

29. Zhang M, Wei Z, Chang S, Teng M and Gong W: A novel member in the cysteine proteinase family. J Mol Biol 358: 97-105, 2006.

30. Satoh R, Koyano S, Takagi K, Nakamura R, Teshima R and Sawada J: Immunological characterization and mutational analysis of the recombinant protein BWp16, a major allergen in buckwheat. Biol Pharm Bull 31: 1079-1085, 2008.

31. Swoboda I, Bugajska-Schretter A, Linhart B, Verdino P, Keller W, Schulmeister U, Sperr WR, Valent P, Peltre G, Quirce S, Douladiris N, Papadopoulos NG, Valenta R and Spitzauer S: A recombinant hypoallergenic parvalbumin mutant for immunotherapy of IgE-mediated fish allergy. J Immunol 178: 6290-6296, 2007.

32. Morita H, Kaneko H, Ohnishi H, Kato Z and Kondo N: Antigen specific immune response to endotoxin-free recombinant P34. Allergy 66: 985-986, 2011.

33. Ji C, Boyd C, Slaymaker D, Okinaka Y, Takeuchi Y, Midland SL, Sims JJ, Herman E and Keen N: Characterization of a 34-kDa soybean binding protein for the syringolide elicitors. Proc Natl Acad Sci USA 95: 3306-3311, 1998.

34. Desaki Y, Miya A, Venkatesh B, Tsuyumu S, Yaname H, Kaku H, Minami E and Shibuya N: Bacterial lipopolysaccharides induce defense responses associated with programmed cell death in rice cells. Plant Cell Physiol 47: 1530-1540, 2006.

35. Hirata T, Osuga Y, Hirota Y, Koga K, Yoshino O, Harada M, Morimoto C, Yano T, Nishii O, Tsutsumi O and Taketani Y: Evidence for the presence of toll-like receptor 4 system in the human endometrium. J Clin Endocrinol Metab 90: 548-556, 2005.

36. Zhao J, Davis LC and Verpoorte R: Elicitor signal transduction leading to production of plant secondary metabolites. Biotech Adv 23: 283-333, 2005.

37. Trompette A, Divanovic S, Visintin A, Blanchard C, Hegde RS, Madan R, Thorne PS, Wills-Karp M, Gioannini TL, Weiss JP and Karp CL: Allergenicity resulting from functional mimicry of a Toll-like receptor complex protein. Nature 457: 585-589, 2009.

38. Clara Sze KW, Kshirsagar HH, Venkatachalam M and Sathe SK: A circular dichroism and fluorescence spectrometric assessment of effects of selected chemical denaturants on soybean (Glycine $\max \mathrm{L}$.) storage proteins glycinin (11S) and $\beta$-conglycinin (7S). J Agric Food Chem 55: 8745-8753, 2007. 